\title{
School- and family-based interventions to prevent overweight in children
}

\author{
Manfred J. Müller*, Sandra Danielzik and Svenja Pust \\ Institut für Humanernährung und Lebensmittelkunde, Christian-Albrechts-Universität zu Kiel, \\ Düstern-brooker Weg 17, D-24105 Kiel, Germany
}

\begin{abstract}
There have been only a few controlled studies on the prevention of overweight and obesity in children and adolescents. These studies differ in relation to strategy, setting, duration, focus, variables of outcome and statistical power, and therefore do not allow general conclusions to be made about the value of preventive measures. All school-based interventions aimed at the prevention of overweight and obesity show some improvement of health knowledge and healthrelated behaviours. Short-term effects on nutritional state seem to be more pronounced in girls than in boys. School-based interventions can reduce the incidence of overweight. There is evidence that families of intermediate and high socio-economic status as well as intact families benefit more from treatment than families sharing other characteristics. Selected prevention in obese children is most successful when children are treated together with their parents. However, there are social barriers limiting the success of family-based interventions. Although some positive effects have been reported, simple interventions in a single area (e.g. a school health education programme) are unlikely to work on their own. The development of effective preventive interventions probably requires strategies that affect multiple settings simultaneously. At present there is no concerted action, rather many strategies in health promotion that are followed in isolation. Faced with the epidemic of overweight there is a need for national campaigns and action plans on childhood overweight and obesity. It is tempting to speculate that this strategy will also increase the value of isolated approaches (e.g. in schools and families).
\end{abstract}

Childhood overweight: Prevention of overweight: Determinants of overweight

The prevalence of obesity and its comorbidities has been steadily increasing over the last 50 years. Obesity, once established, is difficult to treat. Thus, prevention of obesity is on the public health agenda as well as being a highpriority research goal (World Health Organization, 2000; Dietz \& Gortmaker, 2001; Ebbeling et al. 2002; Kumanyika et al. 2002; International Association for the Study of Obesity, 2004). Since the long-term consequences of childhood overweight are well documented, there is a need for early intervention (Dietz, 1998). However, there is only limited research on the prevention of overweight and obesity in children (for reviews, see Campbell et al. 2002; International Association for the Study of Obesity, 2004; James \& Gill, 2004; Müller et al. 2004) and few strategies have been proved to be successful. The present data suggest that school-based interventions as well as familybased interventions may be effective.

\section{Preventive strategies}

Faced with the obesity epidemic this problem needs to be addressed by a public health approach as well as by interventions aimed at individual subjects. In practice, different prevention strategies are used (World Health Organization, 2000). First, intervention strategies are directed at the whole community, with the aim of stabilising or reducing the mean BMI within a population (i.e. universal prevention). Second, selective prevention is directed at high-risk individuals (e.g. children of obese

\footnotetext{
Abbreviations: KOPS, Kiel Obesity Prevention Study; SES, socio-economic status.

*Corresponding author: Professor Dr Manfred James Müller, fax +49 431 8805679, email mmueller@nutrfoodsc.uni-kiel.de
} 
parents). This strategy is concerned with improving the knowledge and skills of individuals to increase competence and personal autonomy and, thus, to prevent excessive weight gain. Third, targeted or secondary prevention or treatment is directed at overweight and obese children and adolescents to prevent further weight gain and/or to reduce body weight. School-based intervention is considered to be universal prevention, whereas family-based intervention may be considered to be selective (in the case of health promotion and education) or even targeted prevention (in the case of a structured treatment programme).

\section{Determinants of weight gain}

Preventive strategies aimed at childhood and adult obesity are based on the knowledge of risk factors and determinants of overweight. Risk factors of childhood obesity include parental overweight, a low socio-economic status (SES), high birth weight, early timing or rate of maturation, low physical activity or high inactivity, dietary intake (including early infant feeding practices) as well as psychological factors (Barker et al. 1996; Ebbeling et al. 2002; International Association for the Study of Obesity, 2004; James \& Gill, 2004; Müller et al. 2004; see Table 1). It is evident that in cross-sectional studies on prepubertal children most of the risk to become overweight is explained by SES and parental overweight. The data also show that there are differences between boys and girls, and also between overweight and obesity. The risk factors are related but their exact relationships at the individual level as well as at a population level are unknown. Although most risk factors for obesity seem to be self evident, their confounding or cumulative effects on the development of obesity, as well as their clustering and their effects over time on the causal pathway to the development of obesity, remain unclear in children (as in adults).

The environmental contribution to the obesity epidemic is evident (Hill \& Peters, 1998; Willett, 2002). Most experts agree that the causes of overweight are environmental, related to living in a world that allows easy access to food and encourages inactivity. In addition to environmental and behavioural determinants of body weight, the importance of fetal nutrition, breast-feeding and genes for body weight and obesity has been demonstrated in animals and man (Sherry \& Dietz, 2004). At present there is no evidence to suggest the benefit of targeted interventions in specific (e.g. genetically-predisposed) subjects. However, there is good evidence for close associations between the nutritional status of parents and that of their children (Vogler et al. 1995; Whitaker et al. 1997; Birch \& Krahnstoever-Davison, 2001; Davison \& Birch, 2001; Danielzik et al. 2002; Müller et al. 2002). Overweight parents frequently have overweight children. In addition to possible genetic links, parents select environments that may promote overweight among their children. This environment includes the parent's own eating behaviours and child feeding practices. Family environment during early and mid childhood have a major impact on food preferences, pattern of food intake, eating style, activity preferences and sedentary or active lifestyles. Detailed knowledge of the interaction between children and adolescents of obese parents and the environment may improve future intervention programmes.

It has been shown recently that a low SES together with parental overweight is a considerable risk factor for childhood overweight (Langnäse et al. 2002, 2003). There is also evidence from studies in prepubertal children that high normal weight and/or normal-weight-overfat children have a high risk of weight gain (Danielzik et al. 2004). Taken together lifestyle variables are considered as minor determinants of body weight that are additive over longer time periods. There is a major influence of socio-economic and environmental factors. It is likely that genetic predisposition adds to the variance in nutritional status. Determinants of children's nutritional status are shown in Fig. 1.

Based on the present knowledge of risk factors and determinants of childhood overweight, the preferred intervention strategies that may be considered are tackling health inequalities, a better school education, counselling pregnant women and/or supporting families. School-based

Table 1. Risk factors for the development of overweight and obesity in 5-7-year-old children (logistic regression analysis; from Danielzik

\begin{tabular}{|c|c|c|c|c|c|}
\hline & \multicolumn{2}{|c|}{ Boys } & & \multicolumn{2}{|c|}{ Girls } \\
\hline & OR & $95 \% \mathrm{Cl}$ & & OR & $95 \% \mathrm{Cl}$ \\
\hline Overweight & & & Overweight & & \\
\hline Low SES & $9 \cdot 8$ & $1 \cdot 8,53 \cdot 1$ & Obese parents & 4.5 & $2 \cdot 3,9 \cdot 0$ \\
\hline Single parenthood & $3 \cdot 4$ & $1 \cdot 7,7 \cdot 1$ & Low SES & $2 \cdot 1$ & $1 \cdot 1,4 \cdot 2$ \\
\hline Obese or overweight parents & $2 \cdot 9$ & $1 \cdot 4,6 \cdot 0$ & Overweight parents & $2 \cdot 1$ & $1 \cdot 2,3 \cdot 8$ \\
\hline Smoking parents & $2 \cdot 6$ & $1 \cdot 1,6 \cdot 3$ & Breast-feeding & $0 \cdot 4$ & $0.2,0.9$ \\
\hline Obesity & & & Obesity & & \\
\hline Smoking parents & $16 \cdot 2$ & $2 \cdot 1,121 \cdot 5$ & Low activity & $8 \cdot 9$ & $1 \cdot 7,46 \cdot 6$ \\
\hline Low birth weight & $13 \cdot 7$ & $1 \cdot 8,105 \cdot 7$ & Obese parents & $6 \cdot 2$ & $2 \cdot 2,18 \cdot 0$ \\
\hline Low SES & $9 \cdot 3$ & $1 \cdot 6,51 \cdot 9$ & High birth weight & $3 \cdot 2$ & $1 \cdot 3,7 \cdot 8$ \\
\hline Obese or overweight parents & $8 \cdot 8$ & $2 \cdot 5,30 \cdot 6$ & & & \\
\hline Single parenthood & $7 \cdot 5$ & $1 \cdot 8,31 \cdot 3$ & & & \\
\hline
\end{tabular}

OR, odds ratio; SES, socio-economic status. 


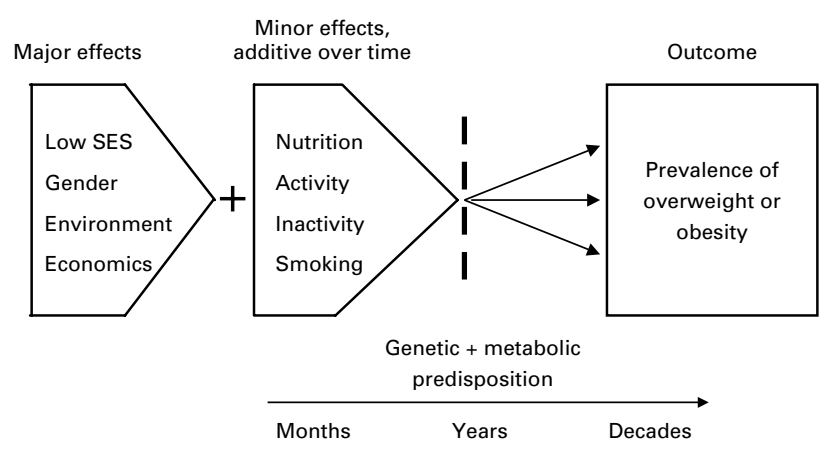

Fig. 1. Schematic representation of the determinants of overweight and obesity. Lifestyle variables show only minor effects that are additive over longer time periods. Socio-economic status (SES) and environmental factors are major determinants. A genetic or metabolic predisposition further adds to the variance in body weight.

interventions (as a measure of universal prevention) cannot, therefore, be considered as suitable intervention strategies to tackle the overweight and obesity epidemic. However, faced with poor nutrition and sedentary lifestyle habits there is no doubt that health promotion within a school setting is necessary. In relation to selected prevention, interventions directed at children with a high normal weight (i.e. $>50$ th percentile and $<90$ th percentile) and at overweight children with obese parents and a low SES seem to be promising. However, considering the number of children affected, this group is not really a selected group.

\section{Outcome measures of school- and family-based interventions}

Outcome measures of obesity prevention are objective measures of the nutritional state (e.g. BMI), comorbidities (e.g. plasma lipid levels), health knowledge, behaviour (e.g. diet, physical activity, sedentary behaviour) and/or competence.

Suitable outcome measures differ between different strategies of prevention. Outcome measures of universal prevention are:

a reduction in the incidence of overweight and of obesity in the general population;

an overall reduction in the average BMI of the population;

improvements in nutritional intake, eating habits, exercise and other health-related activities;

improved knowledge, attitudes and norms relating to nutrition, weight, eating habits and exercise;

decreased rates of comorbidities;

public policy and environmental change indices.

Outcome measures of selective prevention are:

prevention of weight gain;

reduced incidence of overweight or obesity in individuals at risk;

decreased excessive dieting among dieters; improved lifestyle patterns (e.g. healthy diet, more activity, less inactivity).

Outcome measures of targetted prevention are:

a reduction in the number of obese-related comorbidities;

an increase in the number of obese subjects who are successful in attaining and maintaining a relatively small weight loss (e.g. about $10 \%$ of the initial body weight) and a decrease in the number of subjects who gain weight (e.g. $>2 \mathrm{~kg}$ ).

\section{School- and family-based interventions: results of controlled studies}

Interventions to prevent weight gain include: school programmes; correspondence programmes; individual or group counselling, including behaviour change methods; a public health approach. At present there are numerous uncontrolled activities in the area of prevention of childhood overweight. There are also some controlled and randomised studies (Campbell et al. 2002; Summerbell et al. 2003). These studies differ in relation to strategy, setting (school, family, primary care, public health), duration, focus, variables of outcome and statistical power. The studies also differ in relation to the duration of intervention as well as that of the observation period. It is suggested that the follow-up period should be $\geq 6$ months, but one family-based study has reached a maximum follow-up period of 10 years (Epstein et al. 1990). The different authors have used various outcome variables including: BMI; fat mass; indices of risks and comorbidities; indicators of health habits. Most authors report mean values obtained in groups of children (intervention $v$. nonintervention group). At present there is a lack of detailed analysis within specific subgroups and also of data on the effect of intervention on the incidence of overweight and obesity.

\section{School-based interventions}

Studies on school-based interventions have been reviewed extensively (for reviews, see Campbell et al. 2002; International Association for the Study of Obesity, 2004; James \& Gill, 2004; Müller et al. 2004). One of the mostfrequently-cited studies is Planet Health (Gortmaker et al. 1999; Wang et al. 2003). Over a period of 2 years 1295 ethnically-diverse grade 6 and 7 students from public schools (i.e. middle schools) participated in an interdisciplinary intervention aimed at: (1) decreasing TV time as well as consumption of high-fat foods; (2) increasing vegetable intake and moderate-to-vigorous activities. Intervention units were developed with extensive teacher input and focus groups using a variety of methods, including debates, case studies and projects. When compared with controls the prevalence of obesity among girls was found to decrease, while remaining unchanged in boys (see Table 2). Positive and gender-independent changes were reported in the number of hours spent watching TV 
Table 2. Characteristics and outcome of Planet Health and Kiel Obesity Prevention Study (KOPS)

\begin{tabular}{|c|c|c|}
\hline & Planet Health* & KOPS† \\
\hline$n: \mathrm{SI}$ & 641 & 257 \\
\hline NIG & 654 & 257 \\
\hline SI (\%): Boys & $48 \cdot 4$ & 50 \\
\hline Girls & $51 \cdot 6$ & 50 \\
\hline NIG (\%): Boys & 48.5 & 50 \\
\hline Girls & $51 \cdot 5$ & 50 \\
\hline Age (years): SI & $11 \cdot 7$ & $6 \cdot 3$ \\
\hline NIG & $11 \cdot 7$ & $6 \cdot 3$ \\
\hline Ethnicity (\% white) & $63-69$ & $92-95$ \\
\hline Duration of intervention & 2 school years & 2 weeks \\
\hline Follow up & 2 years & 4 years \\
\hline Definition of overweight & $\begin{array}{l}\text { 85th percentile } \\
\text { of TSF and BMI¥ }\end{array}$ & $\begin{array}{l}\text { 90th percentile } \\
\text { of TSF§ }\end{array}$ \\
\hline \multicolumn{3}{|l|}{$\begin{array}{l}\text { SI: Prevalence of } \\
\text { overweight }\end{array}$} \\
\hline ( $\%$ total): Girls & $23 \cdot 6$ & $25 \cdot 4$ \\
\hline Boys & $29 \cdot 3$ & $18 \cdot 9$ \\
\hline $\begin{array}{l}\text { Net differences between } \\
\text { SI and NIG } \\
\text { Prevalence (\%/year) }\end{array}$ & & \\
\hline Girls & $-2 \cdot 8 \|$ & $-3 \cdot 3$ \\
\hline Boys & $+0 \cdot 4 \|$ & $+0 \cdot 4$ \\
\hline \multicolumn{3}{|l|}{ Incidence (\%/year) } \\
\hline Boys & $-1 \cdot 7 \|$ & \\
\hline Girls & $-1 \cdot 0 \|$ & $+0 \cdot 7$ \\
\hline \multicolumn{3}{|l|}{ Remission (\%/year) } \\
\hline Boys & $+6 \cdot 2 \|$ & $+3 \cdot 0$ \\
\hline Girls & $-1 \cdot 4 \|$ & $+1 \cdot 3$ \\
\hline
\end{tabular}

SI, school-based intervention group; NIG, non-intervention group; TSF, triceps skinfold

*From Gortmaker et al. (1999) and Wang et al. (2003).

†From Kiel Obesity Prevention Study (unpublished results).

$\ddagger$ Must et al. (1991).

§Reinken et al. (1980).

\|Gortmaker et al. (1999).

and in nutrition. The reductions in body weight were shown to be related to reductions in the time spent watching TV.

Taking into account all data published in this area it is suggested that school-based interventions alone improve some aspects of healthy behaviours but are without effect on nutritional status in most studies. However, only a very few studies show some positive effects on BMI and/or fat mass. One study suggests gender-specific differences in the effect of intervention on nutritional status (Gortmaker et al. 1999; Wang et al. 2003). The possible influence of SES on outcome has not been considered so far. Since (1) only two intervention studies have specifically addressed the confounding effect of gender and (2) the effect of SES has been ignored, the published effects of school-based interventions on nutritional status may have been camouflaged by the proportion of boys and SES groups within the study populations.

\section{Family-based interventions}

The development of family-based prevention programmes for childhood overweight has been considered as a primary public health goal (International Association for the Study

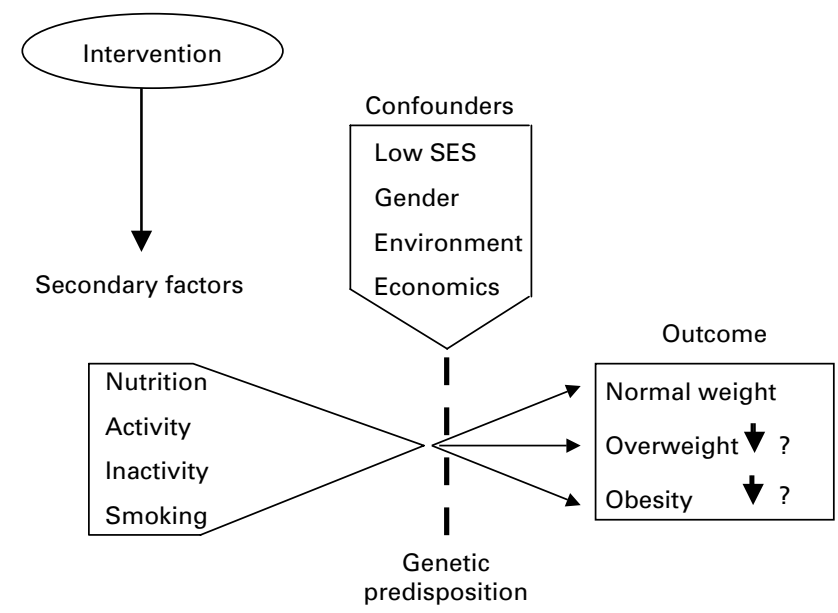

Fig. 2. Schematic representation of the determinants of overweight and outcome of intervention. The effect of lifestyle intervention is affected by gender, socio-economic status (SES) and environmental factors, resulting in a variance in outcome.

of Obesity, 2004). At present most studies in this area have addressed obese children together with their parents. There are also some studies involving parents only. Long-term effective management of overweight and obese children by a family-based intervention has been reported by some authors (Epstein et al. 1990, 1994; Flodmark et al. 1993). The data show that family therapy is effective in preventing the progression of severe obesity in 10-11year-old children (Flodmark et al. 1993). The 1-year increase in BMI was found to be $5 \%$ in the group receiving family therapy $v .12 \%$ in the control group $(P<0.02)$. However, the groups differed in relation to the number of children with severe obesity (i.e. BMI $>30 \mathrm{~kg}$ / $\mathrm{m}^{2}$; one of twenty, five of nineteen, fourteen of forty-eight in the family therapy, conventional treatment and control groups respectively). Epstein et al. $(1990,1994)$ have reported most success when children are treated together with their parents, with the follow-up period lasting $\leq 10$ years. The effectiveness of these interventions, as represented by weight changes, a reduced prevalence of obesity and also lifestyle changes, has been well documented. The 10 -year decreases in the percentage of those who were overweight were reported to be $-7.5 v .+14.3$ in the control group. Most of the family-based intervention studies have resulted in long-term changes in healthrelated behaviours in obese children and adolescents, but have had no, or only moderate, long-term effects on nutritional status.

\section{Bringing the two strategies together: school-based and family-based interventions}

The Kiel Obesity Prevention Study (KOPS) was initiated in 1996 and is planned to run until the year 2009 (Müller et al. 2001, 2004). So far, KOPS has recruited a population of 4997 5-7-year-old, 3580 10-11-year-old and 661 13-15-year-old children. All children were born between 1990 and 1995 in Kiel. So far, 1251 children have been measured twice (i.e. at 5-7 years of age and at 
10-11 years of age). One part of KOPS assesses the longterm effects of 'low level' interventions (1) at school for all children and (2) within 'overweight families' for overweight children. So far, 780 children have undergone a $6 \mathrm{~h}$ curriculum of school intervention within the first classes (i.e. at age 6-7 years); 257 of these children could be re-investigated at age 10-11 years (i.e. after a 4-year follow up). These data have been compared with those for 257 children from non-intervention schools matched for age, gender, BMI, triceps skinfold, parental weight and SES. In addition, ninety-two families with overweight children and parents have been offered a family-based intervention, which takes place within the family setting (i.e. three to five visits at home). A structured sports programme has also been offered to overweight children in this cohort. Sixty-five of these families could be reinvestigated 1 year later.

Outcome measures for KOPS are nutritional state, health habits and risk factors for disease. Family history of diseases, parental weight and height, SES, parental alcohol consumption and smoking habits are also considered as confounding factors. The 4-year-follow-up data show a high persistence of overweight $(77.4 \%$ of children who were overweight at 5-7 years of age remain overweight at 10-11 years of age). The 4-year incidence of overweight is $31.5 \%$ (i.e. $7.9 \%$ /year), with spontaneous remission of overweight reaching 5.3\%/year. Comparing the median of BMI or triceps skinfolds in the population of children in intervention and non-intervention schools has demonstrated a small but beneficial effect. The prevalence of overweight is increased by a factor of 2.2 and 2.0 in the non-intervention and intervention groups respectively. Concomitantly, the 4-year incidence of overweight is reduced in the intervention group $(36.5 \%$ v. $41.7 \%$ respectively). Comparing boys and girls the effect is only seen in girls. SES also has an effect on intervention. The effect is most pronounced in children of high-SES families. When compared with school-based intervention, family-based intervention also shows some positive effects. Within a 1-year observation period family intervention is capable of normalising increases in the BMI of overweight children. However, a low SES serves as a barrier against intervention measures (Langnäse et al. 2004).

\section{Comparing the Kiel Obesity Prevention Study with Planet Health}

In order to put the data into perspective the outcomes of KOPS have been compared with those of Planet Health (Gortmaker et al. 1999; Wang et al. 2003). Table 2 shows that there are some differences between the characteristics of the two studies. However, outcome data show similar effects for magnitude and gender specificity.

\section{Putting the findings into a public health perspective}

It is evident that there is a spontaneous increase in the prevalence of overweight that is explained by both a high persistence plus a high incidence of overweight. The first long-term follow-up data of the KOPS school intervention support the view that prevention decreases the incidence of overweight. Family-based interventions may enhance school intervention. There is evidence that there is a gender effect on outcome. In addition, a low SES serves as a barrier against prevention and treatment. Thus, the major determinants of overweight (see Fig. 1) are confounders of the effect of prevention (Fig. 2).

Faced with the environmental contributors to the obesity problem, societal rather than individual responsibilities are evident. This viewpoint suggests that examining and addressing the obesogenic environment (Egger \& Swinburn, 1997; Egger et al. 2003) is necessary to complement school- and family-based interventions.

\section{Acknowledgements}

The authors wish to thank all co-workers, teachers, parents and children as well as the school physicians of the city of Kiel. KOPS was and is supported by: Deutsche Forschungsgemeinschaft (DFG Mü 714 5-1, 5-2, 5-3); Wirtschaftliche Vereinigung Zucker, Bonn; Precon, Bickenbach; World Cancer Research Fund, UK; Deutsche Angestellten Krankenkasse, Hamburg; Danone Stiftung, München.

\section{References}

Barker DJP, Blundell JE, Dietz WH, Epstein LH, Jeffry RW, Remschmidt H, Rolls BJ, Rössner S \& Saris WHM (1996) Group report: What are the bio-behavioral determinants of body weight regulation? In Regulation of Body Weight. Dahlem Workshop Reports, Life Sciences Research Report no. 57, pp. 159-177 [C Bouchasel and GA Bray, editors] Chichester, West Sussex: Wiley Johnsons.

Birch LL \& Krahnstoever-Davison K (2001) Family environmental factors influencing the developing behavioral controls of food intake and childhood overweight. Pediatrics Clinics of North America 48, 893-907.

Campbell K, Waters E, O'Meara S, Kelly S \& Summerbell C (2002) Interventions for preventing obesity in children. Cochrane Database Systems Review 2:CD001871, Oxford: Update Software; available at http://www.cochrane.org.

Danielzik S, Czwerwinski-Mast M, Langnäse K, Dilba B \& Müller MJ (2004) Parental overweight, socioeconomic status and high birth weight are major determinants of overweight and obesity in 5-7 year old children. Baseline data of the Kiel Obesity Prevention Study (KOPS). International Journal of Obesity 28, 1494-1502.

Danielzik S, Langnäse K, Mast M, Spethmann C \& Müller MJ (2002) Impact of parental BMI manifestation of overweight in 5-7 year old children. European Journal of Nutrition 41, 132-138.

Davison KK \& Birch LL (2001) Childhood overweight: a contextual model and recommendations for future research. Obesity Reviews 2, 159-171.

Dietz WH (1998) Health consequences of obesity in youth: Childhood predictors of adult disease. Pediatrics 101, 518-525.

Dietz WH \& Gortmaker SL (2001) Preventing obesity in children and adolescents. Annual Review of Public Health 22, 337-353.

Ebbeling CB, Pawlak DB \& Ludwig DS (2002) Childhood obesity: public-health crisis, common sense cure. Lancet $\mathbf{3 6 0}$, 473-482. 
Egger G \& Swinburn B (1997) An 'ecological' approach to the obesity pandemic. British Medical Journal 315, 477-480.

Egger G, Swinburn B \& Rossner S (2003) Dusting off the epidemiological triad: could it work with obesity? Obesity Reviews 4, 115-119.

Epstein L, Valoski A, Wing RR \& McCurley J (1990) Ten-year follow-up of behavioral family-based treatment of obese children. Journal of the American Medical Association 264, 2519-2523.

Epstein LH, Valoski A, Wing RR \& McCurley I (1994) Ten year outcomes of behavioral family-based treatment for childhood obesity. Health Psychology 13, 373-383.

Flodmark CE, Ohlsson T, Ryden O \& Sveger T (1993) Prevention of progression to severe obesity in a group of obese schoolchildren treated with family therapy. Pediatrics 91, 880-884

Gortmaker SL, Peterson K, Wiecha J, Sobol AM, Dixit S, Fox MK \& Laird N (1999) Reducing obesity via schoolbased interdisciplinary intervention among youth. Planet Health. Archives of Pediatrics and Adolescent Medicine 153, 409-418.

Hill IO \& Peters IC (1998) Environmental contribution to the obesity epidemic. Science 280, 1371-1374.

International Association for the Study of Obesity (2004) Obesity in children and young people. A crisis in public health. Obesity Reviews 5, Suppl. 1, 1-104.

James WPT \& Gill TP (2004) Prevention of obesity. In Handbook of Obesity. Clinical Applications, 2nd ed., pp. 75-96 [GA Bray and C Bouchard, editors]. New York: Marcel Decker.

Kumanyika S, Jeffery RW, Morabia A, Ritenbaugh C \& Antipatis VJ (2002) Obesity prevention: the case for action. International Journal of Obesity 26, 425-436.

Langnäse K, Asbeck I, Mast M \& Müller MJ (2004) Influence of socioeconomic status on long-term effect of family-based obesity treatment intervention in prepubertal overweight children. Health Education 104, 336-343.

Langnäse K, Mast M, Danielzik S, Spethmann C \& Müller MJ (2003) Socioeconomic gradient in body weight of German children reverse direction between ages 2 and 6 years. Journal of Nutrition 133, 789-796.

Langnäse K, Mast M \& Müller MJ (2002) Social class differences in overweight of prepubertal children in northwest Germany. International Journal of Obesity 26, 566-572.

Müller MJ, Asbeck I, Mast M, Langnäse K \& Grund A (2001) Prevention of obesity-more than an intention. Concept and first results of the Kiel Obesity Prevention Study (KOPS). Inter national Journal of Obesity 25, Suppl. 1, S66-S74.

Müller MJ, Danielzik S \& Spethmann C (2004) Prevention of overweight and obesity. In Obesity in Childhood and Adolescence, pp. 243-263 [W Kiess, C Marcus and M Wabitsch, editors]. Basel, Switzerland: Karger.

Müller MJ, Langnäse K, Danielzik S, Spethmann C \& Mast M (2002) Childhood obesity: the genetic-environmental interface. In Study on Obesity and Functional Foods in Europe, pp. 193-204 [A Palou, ML Bonet and F Serra, editors]. Brussels: European Commission.

Must A, Dallal GE \& Dietz WH (1991) Reference data for obesity. 85th and 95th percentile of body mass index (wt/ht $\left.{ }^{2}\right)$ and triceps skinfold thickness. American Journal of Clinical Nutrition 53, 839-846.

Reinken L, Stolley H, Droese W \& van Ost G (1980) Longitudinale Körperentwicklung gesunder Kinder. II. Grösse, Gewicht, Hautfalten von Kindern im Alter von 1.5-16. Jahren (Longitudinal data of physical growth of healthy children. II. Height, weight, skinfold thickness of children aged 1.5-16 years). Klinische Pädiatrie 192, 25-33.

Sherry B \& Dietz WH (2004) Pediatric overweight: an overview. In Handbook of Obesity. Clinical Applications, 2nd ed. pp. 117-133 [GA Bray and C Bouchard, editors]. New York: Marcel Decker

Summerbell C, Ashton V, Campbell K, Edmunds L, Kelly S \& Waters E (2003) Interventions for treating obesity in children. Cochrane Database System Review 3:CD001872. Oxford: Update Software; available at http://www.cochrane.org.

Vogler GP, Sörensen TIA, Stunkard AJ, Srinivasan MR \& Rao DC (1995) Influences of genes and shared family environment on adult body mass index assessed in an adoption study by a comprehensive path model. International Journal of Obesity 19, 40-45.

Wang LV, Yang Q, Lowry R \& Wechsler H (2003) Economic analysis of a school-based obesity prevention program. Obesity Research 11, 1313-1324.

Whitaker RC, Wright JA, Pepe MS, Seidel KD \& Dietz WH (1997) Predicting obesity in young adulthood from childhood and parenteral obesity. New England Journal of Medicine 337, 869-873.

Willett WC (2002) Balancing life-style and genomics research for disease prevention. Science 296, 695-698.

World Health Organization (2000) Obesity: Preventing and Managing a Global Epidemic. Report of a WHO Consultation. WHO Technical Report Series no. 894. Geneva: WHO. 